\title{
ESPECIALIZAÇÃO DO MERGULHO DE SEGURANÇA PÚBLICA NO CORPO DE BOMBEIROS MILITAR DO ESPÍRITO SANTO - CBMES
}

\author{
Carlos Alberto Mendes de Souza ${ }^{1}$ \\ Cristiano de Assis Silva ${ }^{2}$
}

\section{RESUMO}

O estudo aborda a evolução e o resultado alcançado pelo CBMES na atividade de mergulho desempenhada pela corporação com foco nas especificidades do Mergulho de Segurança Pública. Fruto de apoio incondicional do Comando da Instituição e um trabalho contínuo realizado por oficiais e praças da instituição, principalmente na última década. A atividade de MSP (Mergulho de Segurança Pública) do CBMES (Corpo de Bombeiros Militar do Espírito Santo) se consolida através do trinômio: normatização, configuração de equipamentos e treinamento, tendo como premissas os processos de aprendizado e conhecimento, bem como os procedimentos internos apontados no planejamento estratégico da corporação para o período de 2015/2019.

Palavras-Chave: Capacitação. CBMES. Configuração de equipamentos. Mergulho de segurança pública. Normatização.

\footnotetext{
${ }^{1} 2^{\circ}$ Tenente do Corpo de Bombeiros Militar do Estado do Espírito Santo - CBMES; Mestrando em Segurança Pública pela EIKON University, Bacharel em Administração de Empresas pela Universidade de Vila Velha, Especialista em Mergulho Autônomo pelo CBMES (CEMAut); Public Safety Diving Basics e Advanced Open Water Instructor SSI - Registro 65804; e Mergulhador Técnico Tec 50 PADI/DSAT e Technical Extended Range SSI. Email: carlos.mendes@bombeiros.es.gov.br

${ }^{2}$ Orientador do artigo, Doutorando em Saúde Coletiva pela Cambridge University, Mestre em Ciências da Educação pela Grendel University, Especialista em Saúde Coletiva com ênfase ESF, Especialista em Docência Superior pela Fac. Luso Capixaba, Especialista em Nutrição Clínica pela Univers. Veiga de Almeida, Graduado em Nutrição pela Faculdade Salesiana de Vitória, cristiano.wc32@gmail.com
} 


\title{
SPECIALIZATION OF THE PUBLIC SAFETY DIVING IN MILITARY FIRE CORPS OF ESPÍRITO SANTO STATE - CBMES
}

\begin{abstract}
The study addresses the evolution and the results achieved by the CBMES in the diving activity carried out by the corporation focused on the specificities of the Public Safety Diving. Fruit of unconditional support of the Institution Command and a continuous work carried out by officers and staff of the institution, especially in the last decade. The activity of MSP (Public Safety Diving) of the CBMES (Military Fire Brigade of Espírito Santo) is consolidated through the trinomio: standardization, equipment configuration and training, having as premises the processes of learning and knowledge, as well as internal procedures strategic planning of the corporation for the period $2015 / 2019$.
\end{abstract}

Keywords: Public safety diving. Standards. Training. Configuration. Equipment. Fire Rescue. 


\section{INTRODUÇÃO}

O estudo aborda a evolução e o resultado alcançado pelo CBMES na atividade de mergulho desempenhada pela corporação, com foco nas especificidades do Mergulho de Segurança Pública. Fruto de apoio incondicional do Comando da Instituição e do trabalho contínuo realizado por oficiais e praças da instituição, principalmente na última década, a atividade de MSP (Mergulho de Segurança Pública) do CBMES (Corpo de Bombeiros Militar do Espírito Santo), consolida-se através do trinômio: normatização, configuração de equipamentos e treinamento, tendo como premissas os processos de aprendizado, conhecimento e procedimentos internos apontados no planejamento estratégico da corporação para o período de 2015/2019.

\section{ESPECIALIZAÇÃO DO MERGULHO DE SEGURANÇA PÚBLICA NO CORPO DE BOMBEIROS MILITAR DO ESPÍRITO SANTO - CBMES}

O termo PSD (Public Safety Diving), segundo Karl Shreeves ${ }^{3}$ (PADI, 2006), é utilizado, principalmente, para caracterizar o trabalho de mergulho voltado para a busca e recuperação subaquática de evidências criminais e corpos de vítimas em virtude de acidentes ou crimes.

No caso dos EUA, pode ser desempenhado por agentes de forças de segurança pública e paramédicos, mas também em alguns casos por mergulhadores voluntários especializados que trabalham em estreita colaboração com serviços policiais e de bombeiro. Essa doutrina tem sido estudada e desenvolvida em virtude das necessidades e riscos específicos que o serviço e seus locais de atuação impõem.

No caso específico do Brasil o MSP (Mergulho de Segurança Pública) em resposta a acidentes e crimes em meio aquático é atribuição exclusiva de forças de segurança pública, principalmente dos Corpos de Bombeiros Militares

\footnotetext{
${ }^{3}$ PADI - Professional Association of Diving Instructors, Encyclopedia of Recreational Diving (2006).
} 
Revista Científica do Corpo de Bombeiros Militar de Pernambuco

Seção 1 - Artigos Técnico Científicos

Artigo publicado no Vol.04 №10 - Edição de JUL a DEZ 2018 - ISSN 2359-4837(online)

Versão on-line disponível em: http://www.revistaflammae.com.

(CBM). A Missão Constitucional do Corpo de Bombeiros Militar do ES é estabelecida e descrita no Art. 144, $\S 5^{\circ}$ da Constituição Federal "[...] aos Corpos de Bombeiros Militares, além das atribuições definidas em lei, incube a execução de atividades de Defesa Civil", estando especificada e discriminada na Constituição do Estado do Espírito Santo - já com nova redação da Emenda Constitucional $n^{\circ} 12$, de 20 de agosto de 1997- no Art. 130:

[...] ao Corpo de Bombeiros Militar compete à coordenação e a execução de ações de defesa civil, prevenção e combate a incêndio, perícias de incêndio e explosões em locais de sinistros, busca e salvamento, controle de tráfego de embarcações próximo às praias, rios e lagoas, elaboração de normas relativas à segurança das pessoas e dos seus bens contra incêndios e pânico e outras previstas em lei, no Estado do Espírito Santo.

Nesse contexto a atividade de "busca e salvamento" descrita no texto constitucional estadual é definida abarcando atendimentos de busca e salvamento cuja abordagem envolve: afogamentos; pessoas presas em elevadores; salvamentos em locais de difícil acesso (alturas, montanhas, cavernas, etc.); pessoas presas em ferragens (acidentes automobilísticos); desabamentos, soterramentos, inundações, dentre outras (CBMES $\left.{ }^{4}\right)$.

Embora a missão de busca e salvamento no caso de afogamentos seja determinada e expressa em lei, não há atualmente no Brasil uma normatização federal específica de como o serviço de MSP deve ser realizado, diferente do mergulho comercial ou profissional que é muito bem definido e regulado pela NORMAM 15, que trata das normas da autoridade marítima para atividades subaquáticas no país.

A referida normatização também é específica ao definir no seu Capítulo 1 - Definições, nos itens 0137 e 0139, que não se aplica ao mergulho científico nem ao mergulho amador ou recreativo, visto que no primeiro caso "a atividade não se encontra definida ou regulamentada no âmbito nacional' e no segundo,

\footnotetext{
${ }^{4}$ CBMES - Corpo de Bombeiros Militar do Espírito Santo. Competências. Disponível em: <https://cb.es.gov.br/competencias> Acessado em: 06 de dezembro de 2017.
} 
Revista Científica do Corpo de Bombeiros Militar de Pernambuco

Seção 1 - Artigos Técnico Científicos

Artigo publicado no Vol.04 №10 - Edição de JUL a DEZ 2018 - ISSN 2359-4837(online)

Versão on-line disponível em: http://www.revistaflammae.com.

"regulamentada por normas específicas da Associação Brasileira de Normas Técnicas (ABNT)".

No caso da atividade de mergulho nos CBM, a única menção que a NORMAM 15 faz é acerca da possibilidade de credenciamento de escola, quando diz no Capítulo 3, item 0311, que "os órgãos públicos das esferas federal, estadual ou municipal que ministrem cursos de formação de mergulhadores, visando ao atendimento de suas tarefas institucionais, serão credenciados junto à DPC (Diretoria de Portos e Costas)", no entanto, não há outras definições, por conseguinte, cada ente federativo busca estabelecer e regulamentar o currículo de curso, limites de profundidade para atuação, equipamentos de proteção individual necessários ao serviço, equipe e efetivo mínimo, normas de segurança, etc. (NORMAM 15, 2016).

No CBMES o MSP é um conceito recente, que envolveu a quebra de alguns paradigmas e o enfrentamento de dificuldades estruturais decorrentes, principalmente, de fatores como a cultura de treinamento baseada no módulo "Mergulho Autônomo - Maut" do curso de Mergulho da MB (Marinha do Brasil), que se justificava pela falta de referências nacionais específicas sobre técnicas e procedimentos de mergulho aplicados a segurança pública, e também, por serem os CBM constitucionalmente caracterizados como "Forças auxiliares e reserva do Exército" (Constituição da República Federativa do Brasil. Inciso 6; Parágrafo I; Art. 144. 1988), fazendo com que, no final da década de 80, oficiais e praças do CBMES, buscassem na marinha brasileira, que não tem como seu objetivo precípuo a vocação para o MSP a capacitação para que, então, esse conhecimento pudesse ser difundido dentro da corporação. Outro fator a se considerar foi a forte influência de empresas de mergulho recreativo, tendo em vista que, nas duas primeiras décadas de existência da atividade de mergulho no CBMES, eram estas as fontes mais fáceis e praticamente as únicas disponíveis para suprir as dúvidas, dificuldades internas com a mão de obra para manutenção do equipamento já existente e, a confecção de 
Revista Científica do Corpo de Bombeiros Militar de Pernambuco

Seção 1 - Artigos Técnico Científicos

Artigo publicado no Vol.04 №10 - Edição de JUL a DEZ 2018 - ISSN 2359-4837(online)

Versão on-line disponível em: http://www.revistaflammae.com.

especificações técnicas visando à compra de novos equipamentos (DIAS, 2016).

A nova doutrina que começa a ser estudada no Brasil mostra que o mergulho autônomo dentro dos CBM é apenas uma ferramenta de trabalho para a execução de uma atividade fim e, que carece ser customizada de acordo com as características inerentes ao trabalho desempenhado. Como exemplo das diversas aplicações da "ferramenta" mergulho tem-se basicamente cinco aplicações distintas: Mergulho Militar de Combate, Mergulho Comercial ou Profissional, Mergulho Científico, Mergulho Recreativo/Técnico (amador) e o Mergulho de Segurança Pública. Todas possuem características e finalidades diversas que exigem normatização, configuração de equipamentos e treinamento específico para cada um dos casos. Um mergulhador recreativo, que mergulha por lazer, não necessita da configuração de equipamento, da normatização e, tão pouco do treinamento de um mergulhador de combate da marinha que, dentre outros objetivos e técnicas militares, mergulha com objetivos de demolição, sabotagem ou infiltração em campo inimigo em tempos de guerra; bem como o comercial que, por exemplo, mergulha para polir hélices de navios ou para realizar trabalhos submersos como o corte e solda a centenas de metros abaixo da superfície (PADI, 2006).

Por sua vez, todos possuem necessidades diferenciadas de um MSP que tem por objetivo, na maioria das suas atuações, recuperar evidências criminais ou corpos humanos submersos em água de visibilidade zero, sempre com algum risco de contaminação em virtude dos objetivos e ambientes de atuação e riscos como o enrosco, correnteza, intempéries, ferimentos perfuro cortantes ou contundentes, além de desorientação espacial e afogamento (MENDES, C.A. de Souza. Manual da rotina de serviço ${ }^{5}$, 2016).

\footnotetext{
5 MENDES, C.A. de Souza. Manual da rotina de serviço, procedimentos de atuação, segurança, comunicação e execução de padrões de busca e recuperação subaquática com utilização de cabo guia em ocorrências de mergulho de segurança pública no CBMES. Espírito Santo. 2016).
} 
Revista Científica do Corpo de Bombeiros Militar de Pernambuco

Seção 1 - Artigos Técnico Científicos

Artigo publicado no Vol.04 №10 - Edição de JUL a DEZ 2018 - ISSN 2359-4837(online)

Versão on-line disponível em: http://www.revistaflammae.com.

Atualmente, em um universo de aproximadamente 1.190 homens constantes no efetivo total do CBMES, a corporação conta com $90 \mathrm{ME}$ (Militares Estaduais) no serviço ativo formados no CEMAut (Curso de Especialização em Mergulho Autônomo) que é ministrado pela própria instituição ao longo de seis semanas de curso, com carga horária total de 280h/aula. Estes ME encontram-se distribuídos em toda estrutura organizacional da instituição e consequentemente à disposição das inúmeras atividades atribuídas à corporação (operacionais e administrativas). Desse efetivo total, uma média de 18 estão diretamente à disposição das duas equipes especializadas que atuam em regime de prontidão, treinadas $\mathrm{e}$ equipadas somente com o foco no atendimento do serviço de MSP no estado do ES. Equipes lotadas na Seção de Operações e Salvamento (S.O.S.), pertencente à Primeira Companhia do Primeiro Batalhão de Bombeiros Militares ( $\left.1^{\mathrm{a}} \mathrm{Cia} 1^{\circ} \mathrm{BBM}\right)$, sediada na Capital Vitória, que demostra índices satisfatórios nos resultados apresentados - acima da média esperada (CBMES - Dop, 2017).

Para alcançar tal nível de satisfação e nível de profissionalismo aceitável e adequado, o processo foi longo e iniciou-se quando, em 2002, por determinação do Comandante Geral do CBMES, foi instaurada uma comissão composta por quatro ME com expertise na área de mergulho. $\mathrm{O}$ objetivo era a reformulação da atividade com a elaboração de normas e procedimentos de segurança. Visando criar uma base sólida de conhecimento, essa equipe realizou pesquisas nos locais considerados como referência à época, dentre elas destacam-se as visitas a MB, CBMMG (Corpo de Bombeiros Militar do Estado de Minas Gerais) e ao CBMRJ (Corpo de Bombeiros Militar do Estado do Rio de Janeiro).

Bem como realizou a análise de material didático e programa de curso do Curso de Mergulho Autônomo do CBMPE (Corpo de Bombeiros Militar do Estado de Pernambuco), do material didático de credenciadora de mergulho recreativo internacional disponível à época, NORMAM 15 e Normas de 
Revista Científica do Corpo de Bombeiros Militar de Pernambuco

Seção 1 - Artigos Técnico Científicos

Artigo publicado no Vol.04 №10 - Edição de JUL a DEZ 2018 - ISSN 2359-4837(online)

Versão on-line disponível em: http://www.revistaflammae.com.

Segurança do Ministério do Trabalho (NR 15) - Atividades e Operações Insalubres. Após esta etapa a comissão desenvolveu e apresentou os componentes que fariam então parte do SISMERG (Sistema de Mergulho da Corporação), cujos principais componentes são: Norma de Mergulho $n^{\circ} 01$ do CBMES (NORMERG 01), que versa sobre normas e procedimentos de segurança na atividade de mergulho e um Currículo para o CEMAut/CBMES (atualmente com revisão em andamento), Estágio de Requalificação para Mergulhadores (última revisão: março de 2014), Caderneta de registro de mergulho (última revisão: março de 2014); e Viatura/materiais e equipamentos de mergulho (DIAS, 2016).

Com a formação de novos ME especialistas nesta área de atuação, a partir do ano de 2006, e com o advento da criação dos CDA's/CBMES (Comitês de Desenvolvimento das Atividades Operacionais) que proporcionaram a institucionalização de grupos de pesquisa visando o avanço de doutrina, especificações de materiais, planejamento e processos de ensino nas áreas operacionais da instituição, outras contribuições foram acrescidas, colaborando para o aperfeiçoamento e atualização do trabalho iniciado em 2002 e consolidado através da PORTARIA No 119-R, de 03 de Maio de 2007 que "cria as Normas de Mergulho do Corpo de Bombeiros do Estado do Espirito Santo".

Mais recentemente, já com a DOp (Diretoria de Operações) instituída e trabalhando na atividade de forma atuante, nos anos de 2014 a 2017 a normatização passou por cinco revisões, regulamentadas pelas Portarias $\mathrm{N}^{\circ}$ 318-R e No 332-R, datadas respectivamente de 20 de Março e 19 de Setembro de 2014, Portaria No 361 - R, de 24 de Fevereiro de 2015, Portaria 415-R de 20 de Outubro de 2016 e mais recentemente com a Portaria No 463-R, de 22 de Fevereiro de 2018, onde o Comandante Geral do CBMES regulamenta a atualização da NORMERG 01 , redefinindo e adequando as regras de segurança para realização do serviço levando em consideração as 
Revista Científica do Corpo de Bombeiros Militar de Pernambuco

Seção 1 - Artigos Técnico Científicos

Artigo publicado no Vol.04 №10 - Edição de JUL a DEZ 2018 - ISSN 2359-4837(online)

Versão on-line disponível em: http://www.revistaflammae.com.

necessidades específicas da atividade de MSP (CBMES, Coletânea de Portarias, 2015).

Tais revisões fizeram-se necessárias em virtude da adequação da redação normativa à realidade vivenciada pela instituição a cada época, uma vez que, mesmo que já estivesse bem definido e traçado o rumo para a evolução da atividade de mergulho no CBMES, não caberia possuir uma normatização que fosse muito avançada, porém, inexequível no dia a dia operacional, seja por indisponibilidade de equipamentos, seja por capacitação deficiente, logo, a cada passo alcançado nesses dois sentidos, a redação foi modificada para acompanhar a evolução técnico profissional da Instituição (CBMES - Dop, 2017).

Observa-se então que desde 2002 até os dias atuais o ciclo de gestão da atividade é uma preocupação constante e vem sendo executada sistematicamente, buscando controle e melhoria contínua da norma, pesquisa e aquisição de EPI's (Equipamentos de Proteção Individual) adequados, além da especialização dos mergulhadores através da aquisição de conhecimentos "extramuros", com informações advindas de consensos, normas e das várias credenciadoras internacionais atualmente existentes, além de técnicas e procedimentos próprios para o serviço de MSP.

Importante ressaltar que a NORMERG 01, a configuração de equipamentos e os procedimentos desenvolvidos e adotados no CBMES atualmente, de forma total ou parcialmente, é tema de estudo de alguns CBM nos estados do Paraná, Roraima, Rondônia, Alagoas, Bahia, Paraíba, Rio de Janeiro, Mato Grosso, Goiás e Pará (DIAS, 2016).

\section{CAPACITAÇÃO CONTINUADA E SAÚDE DO MSP NO CBMES}

A existência de formação continuada para o efetivo, bem como a manutenção de uma equipe especializada e dedicada ao serviço, tem sido vital para consolidação dessa nova doutrina. Para a revisão e manutenção dos 
Revista Científica do Corpo de Bombeiros Militar de Pernambuco

Seção 1 - Artigos Técnico Científicos

Artigo publicado no Vol.04 №10 - Edição de JUL a DEZ 2018 - ISSN 2359-4837(online)

Versão on-line disponível em: http://www.revistaflammae.com.

conhecimentos adquiridos e atualização de novos procedimentos, tecnologias e conceitos, o CBMES realiza a cada dois anos o Estágio de Requalificação de Mergulhadores de Segurança Pública. Esta requalificação, prevista na NORMERG 01, é obrigatória para os mergulhadores que estão à disposição da atividade ou que participam de qualquer parte do processo de ensino na capacitação de novos MSP na corporação, mas também, de suma importância para os que já desempenharam a atividade, mas que por necessidades institucionais, encontram-se em outras funções, o que naturalmente faz com que percam o contato e consequentemente a destreza com a especialização de MSP.

A cada edição da Requalificação uma média de $60 \mathrm{ME}$ passa pelo estágio. Na última edição, ocorrida no ano 2016, 60 ME do CBMES, 01 do estado de Goiás e 02 do Rio de Janeiro realizaram a Requalificação em uma das oito turmas distribuídas ao longo de 75 dias de instrução.

Por orientação expressa na NORMERG 01, antes de participarem das instruções, os ME devem passar por uma série de exames médicos específicos (Anexo 4 da NORMERG 01), e posteriormente avaliados por um médico hiperbárico. Tal avaliação é acompanhada da Ficha de avaliação médica para MSP do CBMES (Anexo 8 da NORMERG 01) que objetiva investigar, nas diversas especialidades clínicas, a saúde desses profissionais em busca de condições físicas e fisiológicas que poderão colocá-los em perigo quando submetidos ao ambiente subaquático/hiperbárico e assim verificar se o efetivo ainda permanece apto para o serviço.

Mesmo com a atenção quanto ao atendimento à normatização, o maior objetivo é assegurar as características desejáveis do serviço, como: qualidade, segurança, confiabilidade, eficiência, além de equipamentos e treinamentos voltados para mitigar os riscos do serviço, é possível que possam acontecer acidentes e incidentes, já que o ambiente de ocorrência do MSP carrega um alto índice de periculosidade, além, como já mencionado da insalubridade comum ao meio hiperbárico. 
Revista Científica do Corpo de Bombeiros Militar de Pernambuco Seção 1 - Artigos Técnico Científicos

Artigo publicado no Vol.04 №10 - Edição de JUL a DEZ 2018 - ISSN 2359-4837(online)

Versão on-line disponível em: http://www.revistaflammae.com.

Mediante ao exposto, fazia-se necessário estabelecer um Hospital de referência e o desenvolvimento de um Plano de Emergência a fim de dar o suporte especializado a eventuais acidentes do tipo ED (Enfermidade Descompressiva) durante o serviço. Tratava-se de uma lacuna importante no SISMERG que era possuir um guia próprio de procedimentos para prevenção, atendimento e tratamento definitivo a acidentes descompressivos sofridos por um ME do CBMES durante atendimento a uma ocorrência de MSP (CLENDENEN, 1996).

Embora conhecida, durante o acidente descompressivo sofrido por um ME em serviço no ano de 1997 e outro em 2011, ficou evidente a necessidade de possuir uma forma institucionalizada padrão em lidar com esse tipo de situação. No ano seguinte ao último acidente, no ano de 2012, dois ME foram enviados a Cidade de São Paulo - SP para participação no Curso de Medicina Hiperbárica e Subaquática ministrado pela "Divers Alert Network" - DAN, uma organização mundial, sem fins lucrativos, formada por médicos e pesquisadores voluntários de diversas nacionalidades e voltada para a segurança no mergulho.

Como resultado deste treinamento, no mesmo ano, é redigido o Manual de ED (Enfermidade Descompressiva - Doença Descompressiva e Síndrome da Hiperdistensão Pulmonar) e Primeiros Socorros específicos e o POP (Procedimento Operacional Padrão) de Primeiros Socorros para ED, respectivamente o anexo 1 e Anexo 1.1 da NORMERG 01, além do primeiro contato com um médico capixaba referência no assunto e que após dois anos de trocas de informações resultaria em um convênio com um Centro de Medicina Hiperbárica para o atendimento e tratamento de um acidente do tipo ED. Em seguida para estabelecer e padronizar a resposta a este tipo de acidente foi desenvolvido e incorporado a norma o Plano de Emergência, anexo 9 da NORMERG 01, integrando as agências signatárias envolvidas (DIAS, 2016). 
Revista Científica do Corpo de Bombeiros Militar de Pernambuco

Seção 1 - Artigos Técnico Científicos

Artigo publicado no Vol.04 №10 - Edição de JUL a DEZ 2018 - ISSN 2359-4837(online)

Versão on-line disponível em: http://www.revistaflammae.com.

\section{CONFIGURAÇÃO DE EQUIPAMENTOS E SISTEMATIZAÇÃO DO SERVIÇO DE MSP NO CBMES}

Além da normatização, os equipamentos de mergulho utilizados no CBMES também evoluíram com o passar dos anos, devido ao conhecimento adquirido sobre novas tecnologias e de como esses equipamentos estão padronizados e, são empenhados no serviço realizado por times de PSD nos EUA.

Uma vez que a configuração necessária está intimamente ligada aos objetivos específicos da missão a ser desempenhada e, nem todos os equipamentos disponíveis no mercado se adequam às características do trabalho, até o ano de 2007 a corporação utilizava uma configuração de equipamentos integralmente recreativos, com roupas úmidas (neoprene), máscaras semifaciais, uma única fonte de ar respirável, falta de redundância na ferramenta de corte, falta de comunicação oral com e entre os mergulhadores, etc. - o que não condizia com as necessidades do serviço (FEMA, 2007).

A partir de 2007 os primeiros computadores de pulso para mergulho e nadadeiras com molas integradas de aço inoxidável para fixação foram adquiridos. Estas aquisições ocorreram em virtude de uma visão, embora que incipiente, da necessidade de melhores equipamentos adaptados à atividade de MSP. Nesse mesmo ano foi iniciado o estudo para a sistematização e uniformização dos padrões de busca e recuperação subaquática com a utilização de cabo guia, melhores formas de acondicionamento desses cabos e o estabelecimento de uma rotina própria para o serviço dos mergulhadores da corporação.

Este estudo culminou, no ano de 2011, com a primeira publicação do Manual da Rotina de Serviço, Procedimentos, Comunicação e Padrões de Busca e Recuperação Subaquática com uso de cabo guia em ocorrências de mergulho de segurança pública no CBMES (Anexo 2 da NORMERG 01), que atualmente se encontra em processo de revisão com o objetivo de agregar 
Revista Científica do Corpo de Bombeiros Militar de Pernambuco

Seção 1 - Artigos Técnico Científicos

Artigo publicado no Vol.04 №10 - Edição de JUL a DEZ 2018 - ISSN 2359-4837(online)

Versão on-line disponível em: http://www.revistaflammae.com.

conceitos atuais, melhores explicações e ampliação com a divulgação sobre a questão do risco de contaminação, formas de mitigação desse risco e o processo de descontaminação dos MSP do CBMES (USEPA, 2016).

Em 2014 dando continuidade às mudanças, porém agora já com a doutrina de MSP melhor estudada e compreendida, com foco na melhor adaptação ao serviço, foram adquiridas e empregadas no serviço as primeiras MFF (Máscaras Full Face) com sistema de fonia o que foi um marco na adoção de equipamentos específicos para a realização do trabalho (SESP, 2015).

No ano de 2016 uma maior quantidade dessas máscaras foi adquirida para completar a carga desses equipamentos e possibilitar assim que estas passassem a ser equipamento de uso padrão para o atendimento de ocorrências de MSP no CBMES. Nos três anos seguintes em decorrência da continuidade no estudo da doutrina, mais equipamentos e procedimentos de segurança foram especificados, adquiridos, testados e adotados. Dentre os novos incrementos destacam-se os cilindros de resgate (S30 como "bail out"), para permitir autossuficiência, redundância de gás respirável em casos de emergência na fonte principal, bem como, auxiliar no processo de descontaminação do mergulhador, novas ferramentas de corte específicas para resposta ao enrosco causado por cabos e redes comumente presentes nos ambientes de atuação, mosquetão de segurança no cabo guia como "back up" de ligação entre o Mergulhador de fundo e o Apoio de superfície, além das roupas secas específicas para águas contaminadas, comutadores de gás que evitam a necessidade de retirada da MFF em uma condição de emergência por falta de gás em águas contaminadas e agentes descontaminantes para riscos microbiológicos (PSDiver, 2014).

Embora o MSP seja habitualmente realizado em todo o mundo em profundidades dentro dos limites sem descompressão e em profundidades de até 30 metros, as peculiaridades geográficas regionais, bem como as atividades econômicas e de pesquisa científica, comuns a cada região, podem exigir do poder público equipes especializadas e treinadas para atuarem em 
Revista Científica do Corpo de Bombeiros Militar de Pernambuco

Seção 1 - Artigos Técnico Científicos

Artigo publicado no Vol.04 №10 - Edição de JUL a DEZ 2018 - ISSN 2359-4837(online)

Versão on-line disponível em: http://www.revistaflammae.com.

resposta em ambientes diferenciados onde o treinamento, equipamentos e técnicas disponíveis aos MSP convencionais não permitem a realização do trabalho com segurança e eficiência.

Diante disso, em virtude do estado do ES possuir uma vocação portuária, petrolífera e de pesquisa oceanográfica cada dia mais desenvolvida, no ano de 2014 foram adquiridos os equipamentos para Mergulho Técnico como cilindros duplos com "manifolds", cilindros S40 destinados à descompressão, células de ar tipo asa com maiores volumes, "backplates e harness", reguladores de primeiro e segundo estágio de alto desempenho, roupas semi secas para exposição térmica, computadores multigás, dentre outros, visando possibilitar uma equipe de cinco MSP da corporação, que foram devidamente treinados e certificados no ano de 2017, a realizarem imersões descompressivas, permitindo-lhes, inicialmente, trabalhar até 50 metros de profundidade com equipamentos de mergulho de circuito aberto. Informações detalhadas sobre esta temática em: CBMES - Corpo de Bombeiros Militar capacita equipe de militares a realizar mergulhos técnicos de até 50 metros de profundidade com troca de gás, múltiplos patamares de descompressão e emprego de equipamentos especializados ${ }^{6}$.

\section{RESULTADOS E DISCUSSÕES}

Visando quantificar os resultados obtidos pelas equipes de mergulho do CBMES, a DOp iniciou o mapeamento de todas as ocorrências atendidas a partir de 25 de dezembro de 2015, extraindo informações adicionais das que são comumente preenchidas nos B.O. (Boletins de Ocorrência). Por meio dos números observados, dentre outras informações, pôde-se monitorar os atendimentos realizados, traçando um perfil das imersões, dados sobre as

6 Disponível em: <https://cb.es.gov.br/Not\%C3\%ADcia/corpo-de-bombeiros-militar-capacitaequipe-de-militares-a-realizar-mergulhos-tecnicos-de-ate-50-metros-de-profundidade-comtroca-de-gas-multiplos-patamares-de-descompressao-e-emprego-de-equipamentosespecializados> Acessado em: 19 de dezembro de 2017. 
Revista Científica do Corpo de Bombeiros Militar de Pernambuco Seção 1 - Artigos Técnico Científicos

Artigo publicado no Vol.04 №10 - Edição de JUL a DEZ 2018 - ISSN 2359-4837(online)

Versão on-line disponível em: http://www.revistaflammae.com.

vítimas e ambientes de atuação e índices de recuperação, informações que servem como base de dados para programas de educação e conscientização da população e de turistas no ES, ao tratar-se de acidentes em meio líquido, tendo ênfase o afogamento, inclui-se como fonte de dados para a orientação interna do serviço. (CBMES - Formulário de estatística MSP, 2017).

Gráfico 01 - Tipo de ambiente de trabalho

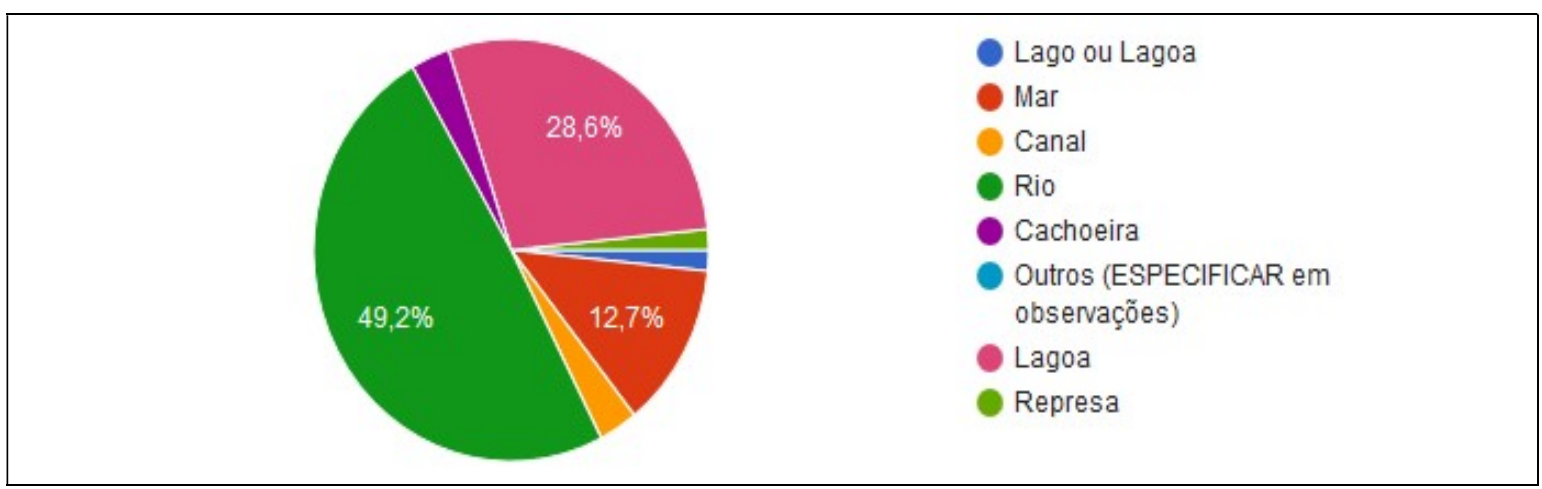

Fonte: Os autores (2017).

Observando os dados acima é possível verificar que quase metade das buscas subaquáticas no ES é realizada em rios (49,2\%), considerados ambientes de difícil atuação em virtude de visibilidade restrita ou nula, pontos de enrosco no fundo, risco de ferimentos em entulhos submersos e presença de correnteza.

Os outros ambientes com maior número de ocorrências são lagos ou lagoas $(28,6 \%)$ e no mar $(12,7 \%)$, neste último, dado o elevado índice de suicídios na Ponte Deputado Darcy Castello de Mendonça ( $3^{\circ}$ Ponte), que liga as cidades de Vitória e Vila Velha, e não por haver grande incidência de óbitos nas praias capixabas. 
Revista Científica do Corpo de Bombeiros Militar de Pernambuco

Seção 1 - Artigos Técnico Científicos

Artigo publicado no Vol.04 №10 - Edição de JUL a DEZ 2018 - ISSN 2359-4837(online)

Versão on-line disponível em: http://www.revistaflammae.com.

Segundo fonte do Jornal "Gazetaonline", no ano de 2016 foram registrados 10 óbitos e em 2017, somente no período compreendido entre janeiro a agosto, 04 mortes (GAZETAONLINE. 2017).

Em relação às mortes por afogamento a impressão de que o grande problema está no litoral é enganosa, pois, de 20 anos para cá os guarda-vidas dos Corpos de Bombeiros de todo país atuam de forma excepcional no litoral e os números mostram esta conquista. Houve uma significativa redução de números de afogamentos no litoral o que não corresponde nas áreas do interior, onde há muito que fazer. Quando particularizamos qualquer estado brasileiro, verificamos que mesmo naqueles com litoral as mortes estão ocorrendo principalmente no interior. (SZPILMAN, 2011).

Em relação ao ambiente de atuação, os tipos de fundo variam muito, especialmente entre lagos e rios, em contraste com o oceano. Ao observar o tipo de fundo, deve-se levar em consideração a possibilidade da área apresentar lixo espalhado, tais como objetos afiados, destroços ou entulho, que podem ser um risco potencial. Alguns tipos de fundo estão cobertos por vidro quebrado, linha de pesca ou outros objetos perigosos, e deve-se estar atento a estes detalhes (SSI, 2011).

Ao analisar a recuperação dos alvos submersos (vítimas e evidências criminais), os números obtidos mostram que em $81 \%$ das imersões o alvo foi recuperado ou então se confirmou através do mergulho a não existência de um alvo submerso; $77,8 \%$ da cor azul somado a $3,2 \%$ da parte laranja do gráfico, uma vez que a parte laranja se refere a mergulhos realizados com êxito, muito embora não houvesse uma vítima submersa e tais mergulhos foram realizados justamente para esse fim, o de "eximir possibilidade", ou seja, havia a solicitação por uma suspeita de óbito no local, porém, com o mergulho foi possível atestar que não havia um alvo submerso, observe o Gráfico 2.

\footnotetext{
${ }^{7}$ GAZETAONLINE. Especial Pela Vida. Índice de mortes na $3^{\mathrm{a}}$ Ponte é o menor dentro do ES, diz psicóloga. Disponível em: $<$ https://www.gazetaonline.com.br/especiais/reportagens/2017/08/especial-pela-vida1014095823.html\#59a7df7a44efc> Acesso em: 06 de dezembro de 2017.
} 
Revista Científica do Corpo de Bombeiros Militar de Pernambuco

Seção 1 - Artigos Técnico Científicos

Artigo publicado no Vol.04 №10 - Edição de JUL a DEZ 2018 - ISSN 2359-4837(online)

Versão on-line disponível em: http://www.revistaflammae.com.

Gráfico 02 - Percentual de recuperação dos alvos

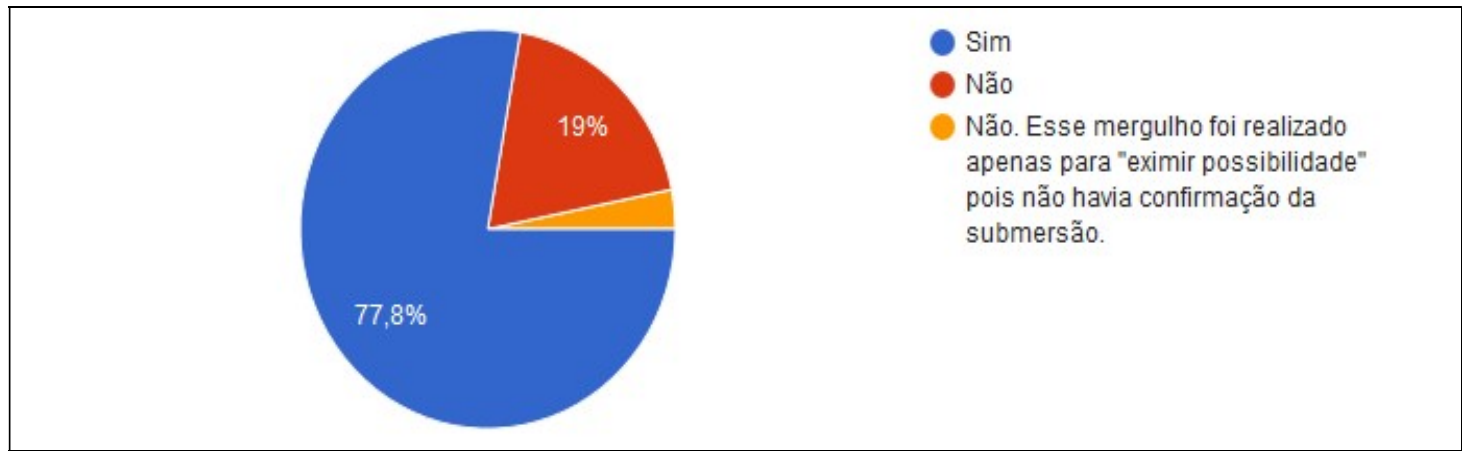

Fonte: Os autores (2017).

Quando um padrão de busca completou uma área de pesquisa, não deve haver dúvidas de que a área foi coberta. Se o objeto não foi encontrado, deve-se ser capaz de concluir com alguma certeza que o objeto não está na área. Caso contrário, o tempo e o esforço colocados na execução do padrão foram desperdiçados. O padrão de busca escolhido deve ser capaz de confirmar que o mergulhador cobriu cada centímetro do perímetro (SSI, 2016).

E ao considerar os motivos que impediram a recuperação, observa-se que em quase $10 \%$ a questão ambiental foi determinante - informações no Gráfico 3 - tendo em vista que: 1 - se for verificada correnteza expressiva no local, é preciso ponderar que pode se tornar fator impeditivo para a realização do mergulho; 2- a imprecisão nas informações fornecidas à equipe de mergulho pela(s) testemunha(s) no local pode inviabilizar o sucesso de uma operação de busca e recuperação subaquática, uma vez que a pesquisa não será realizada no local correto $(4,8 \%)$ e ainda a falta de veracidade no fator gerador da ocorrência (3,2\%). É muito difícil localizar um objeto debaixo de água, mesmo que ele seja grande, a menos que possua uma ideia do local onde iniciar a busca. 
Revista Científica do Corpo de Bombeiros Militar de Pernambuco

Seção 1 - Artigos Técnico Científicos

Artigo publicado no Vol.04 №10 - Edição de JUL a DEZ 2018 - ISSN 2359-4837(online)

Versão on-line disponível em: http://www.revistaflammae.com.

O meio ambiente tem um grande papel na busca, como a profundidade, temperatura da água, visibilidade e movimento da água (correnteza). Quanto maior e mais funda for à área de busca (ou quanto menor for o objeto), mais importante se torna a localização exata de onde iniciar a busca. Quanto mais exata for à indicação da localização, mais fácil se torna a condução da busca e mais altas são as probabilidades de sucesso. Deve-se saber qual é a última localização conhecida do objeto e qual é a área aproximada de busca. Ao estimar qual foi o último ponto onde o objeto foi visto, devem-se levar em consideração as correntes e os movimentos da água porque esses fatores podem afetar o local onde o objeto irá depositar-se no fundo (SSI, 2011).

Gráfico 03 - Principais causas na não recuperação dos alvos

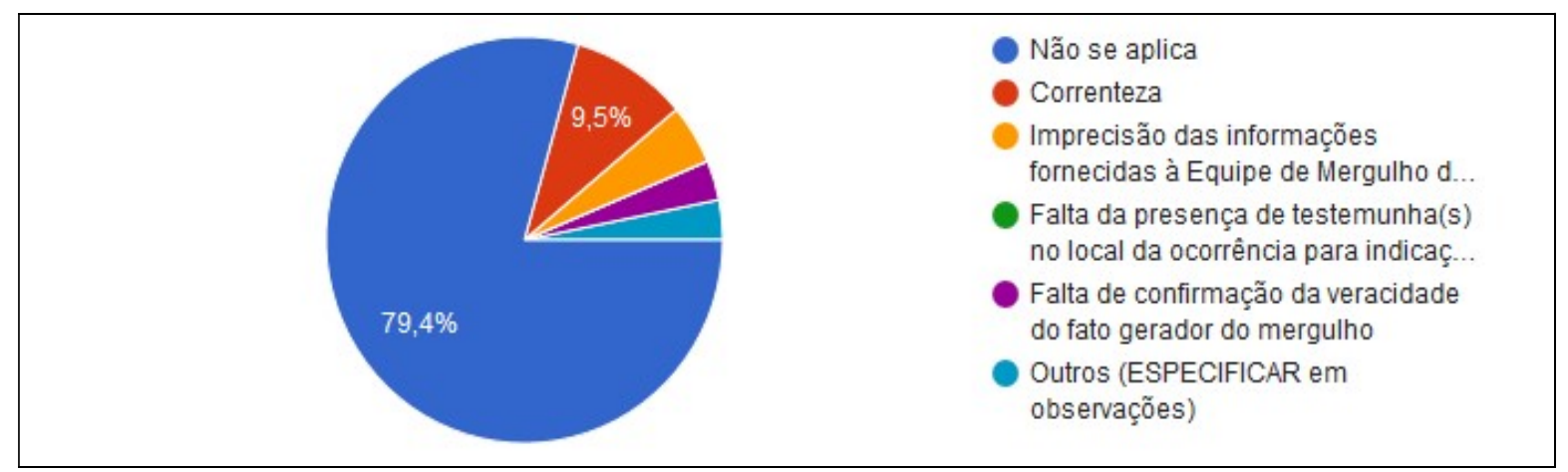

Fonte: Os autores (2017).

Ao analisar o Gráfico 4, que apresenta a quantidade de imersões necessárias para a recuperação de alvos fica evidenciado que na maioria das ocorrências são necessárias poucas imersões para o cumprimento da missão. Este aspecto, que talvez pareça sem muita importância, faz a diferença no resultado final do serviço de MSP, principalmente quando tratamos de recuperação de corpos humanos. Em virtude da comoção pública envolvida nessas ocorrências, exige-se uma resposta rápida para a sociedade, incluindo- 
Revista Científica do Corpo de Bombeiros Militar de Pernambuco

Seção 1 - Artigos Técnico Científicos

Artigo publicado no Vol.04 №10 - Edição de JUL a DEZ 2018 - ISSN 2359-4837(online)

Versão on-line disponível em: http://www.revistaflammae.com.

se a manutenção da integridade do corpo para fins de perícia criminal e também das cerimônias como velórios e funerais.

Gráfico 04 - Número de imersões necessárias para recuperação dos alvos

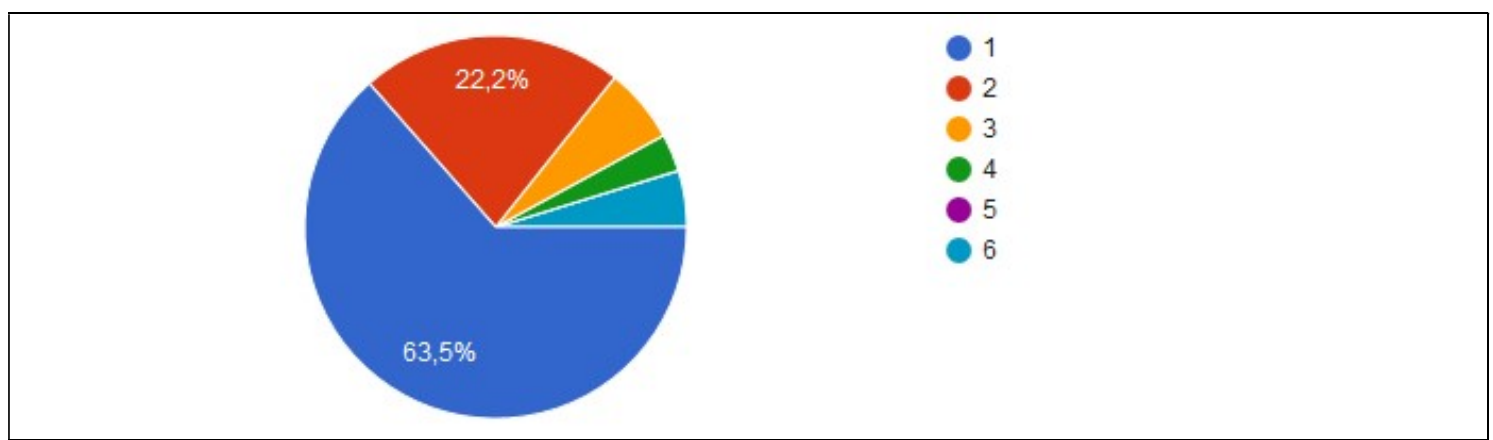

Fonte: Os autores (2017).

De todas as ocorrências analisadas, em mais da metade dos casos $63,5 \%$, foi necessário apenas uma imersão para obter sucesso na recuperação, seguido por $22,2 \%$ dos atendimentos que necessitaram de duas imersões.

Tal fato se deve a vários fatores, dentre eles, cita-se: 1- o eficiente treinamento das equipes; 2- precisão na coleta de informações no local da ocorrência; 3- correto dimensionamento da área e; 4- escolha do padrão de busca e recuperação subaquático mais adequado e eficiente para o local.

Muitas operações de busca e recuperação subaquática ocorrem em águas que não são ideais para o mergulho, onde a visibilidade, por exemplo, pode ser extremamente baixa. Além disso, quanto mais longa for à duração da busca, pior a visibilidade se torna para o mergulhador à medida que a areia $\mathrm{e}$ os sedimentos são remexidos ou agitados, e à medida que a visibilidade diminui, torna-se mais difícil para o mergulhador manter o sentido de orientação.

Águas extremamente escuras e/ou frias também podem causar vertigem ou tontura. Naturalmente, chega um ponto em que o mergulhador não 
Revista Científica do Corpo de Bombeiros Militar de Pernambuco Seção 1 - Artigos Técnico Científicos

Artigo publicado no Vol.04 №10 - Edição de JUL a DEZ 2018 - ISSN 2359-4837(online)

Versão on-line disponível em: http://www.revistaflammae.com.

consegue continuar a trabalhar nessas más condições e a busca deve ser adiada ou totalmente cancelada. Finalmente, a segurança do mergulhador e da sua equipe irá determinar quando a busca irá continuar (SSI, 2011).

Ao analisar apenas as buscas por vítimas humanas submersas, observa-se que $82,5 \%$ dos casos são para recuperação de vítimas do sexo masculino, ver Gráfico 5. A cada 84 minutos morre um brasileiro afogado, são 17 óbitos diariamente no Brasil e quando consideramos o sexo, em média, o homem morre por afogamento seis vezes mais do que a mulher (SOBRASA ${ }^{8}$ 2015).

Do total de atendimentos para busca e recuperação subaquática de vítimas realizada pelo CBMES, apenas 9,5\% das recuperações é em resposta a óbitos correspondentes a vítimas do sexo feminino, sendo o percentual restante $-7,9 \%$ dos acionamentos, correspondentes a recuperação de alvos materiais e não vítimas humanas.

Gráfico 05 - Sexo das vítimas recuperadas.

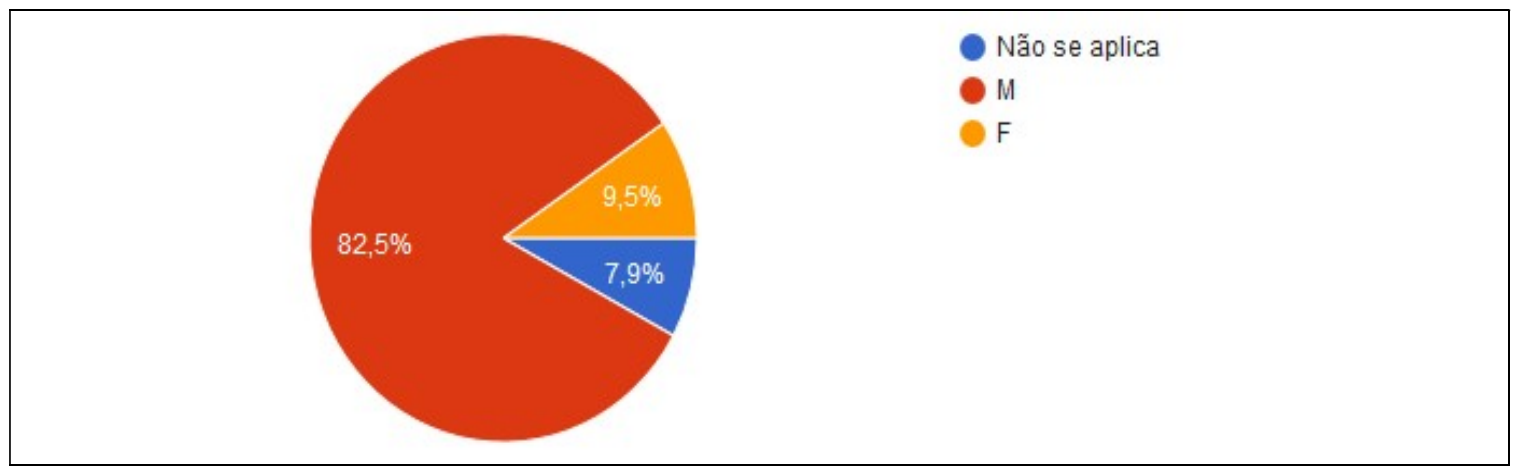

Fonte: Os autores (2017).

Quando abordamos a faixa etária, chama-se atenção para a prevalência dos óbitos em idade jovem, observe o Gráfico 6, (que, infelizmente, acompanha a estatística nacional), visto que: ${ }^{8}$ SOBRASA - Sociedade Brasileira de Salvamento Aquático. Afogamentos. O que está
acontecendo? Boletim Brasil (2015). 


\section{Revista FLAMMAE}

Revista Científica do Corpo de Bombeiros Militar de Pernambuco

Seção 1 - Artigos Técnico Científicos

Artigo publicado no Vol.04 №10 - Edição de JUL a DEZ 2018 - ISSN 2359-4837(online)

Versão on-line disponível em: http://www.revistaflammae.com.

- 39,7\% dos óbitos estão compreendidos entre 05 a 29 anos;

- seguido de pessoas mais velhas, com dados obtidos de $33,4 \%$ para idades de 30 a 49 anos;

- 14,3\% dessa amostragem verificamos a faixa etária de 50 a 59 anos e;

$-4,8 \%$ de 60 a 69 anos.

\section{Gráfico 06 - Faixa etária das vítimas recuperadas}

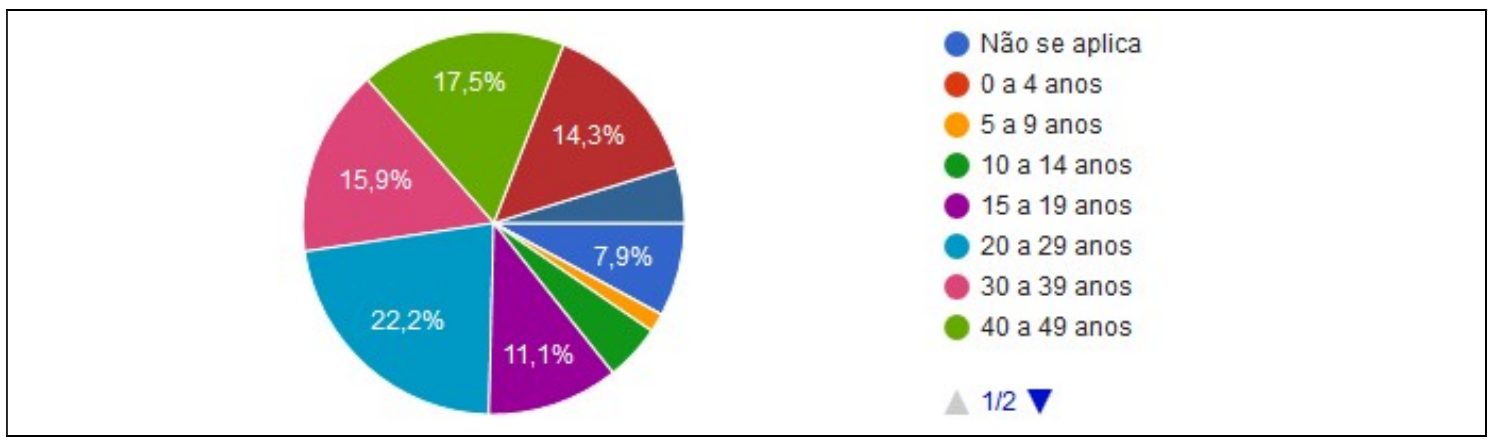

Fonte: Os autores (2017).

O próximo Gráfico demonstra a provável causa da submersão das vítimas e consequentemente ao óbito, Gráfico 7 , ressalta-se que a ingestão de bebida alcoólica $(34,9 \%)$ apresenta-se como a principal causa; a falta de habilidade da vítima em meio aquático e o acometimento de câimbras, mal súbitos, etc. totalizam $22,2 \%$ das causas e, $17,5 \%$ dos casos em decorrência de esforço físico superior a capacidade da vítima, mesmo ela possuindo habilidade em meio aquático.

Os suicídios, a falta de supervisão direta dos pais sobre os filhos em ambientes aquáticos e a queda de embarcações e/ou naufrágios completam essa estatística. Curiosamente, apenas no ano de 2015, 6.043 brasileiros morreram em decorrência de afogamento.

A estatística nacional aponta que $75 \%$ dos óbitos se dão em ambientes como rios e represas e, que os homens morrem em média seis vezes mais do que mulheres. Quase metade dos óbitos no Brasil ocorre em uma faixa etária 
Revista Científica do Corpo de Bombeiros Militar de Pernambuco

Seção 1 - Artigos Técnico Científicos

Artigo publicado no Vol.04 №10 - Edição de JUL a DEZ 2018 - ISSN 2359-4837(online)

Versão on-line disponível em: http://www.revistaflammae.com.

de até 29 anos. Usualmente associada a uma situação de lazer, o afogamento sempre provoca uma surpresa nos familiares, que jamais haviam admitido antes a possibilidade dessa tragédia.

Gráfico 07 - Causas possíveis que levaram a submersão da vítima.

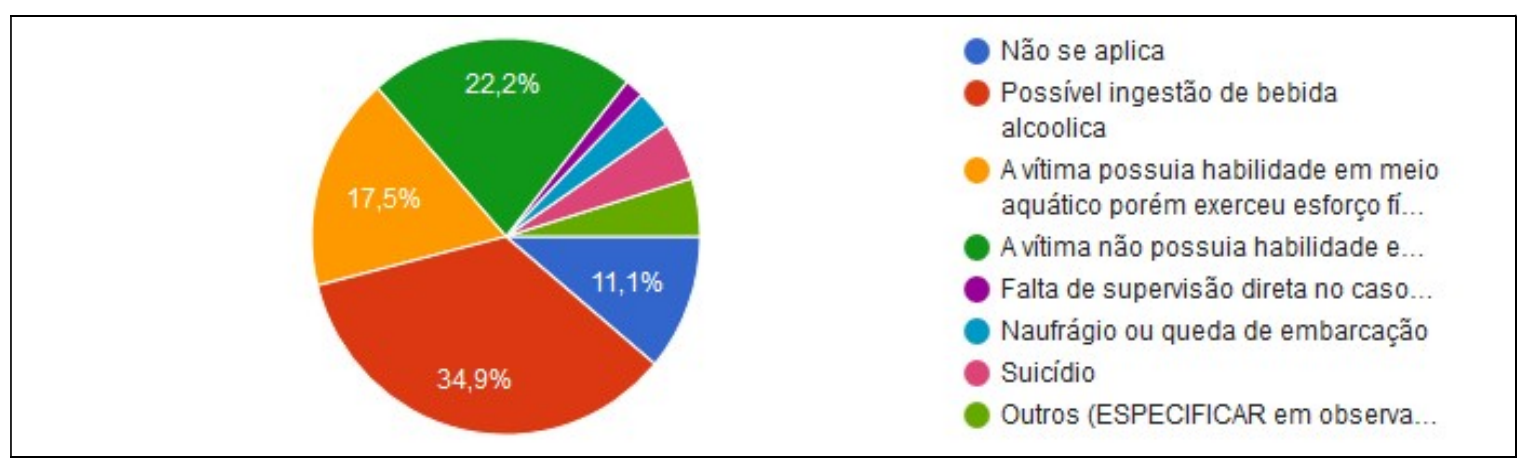

Fonte: Os autores (2017).

É considerado um incidente silencioso, muita das vezes atribuída a uma "fatalidade". Ocorre no ambiente extra-hospitalar e por ter pouca ou nenhuma repercussão, não ganha a notoriedade e a atenção que necessita. Programas de prevenção são a resposta que necessitamos para reduzir esta catástrofe diária que é o afogamento no país (SOBRASA, 2015). Muitas vezes, as buscas são lentas e demoradas e a frustração de membros da família, especialmente em afogamentos, pode se reverter em um sentimento de raiva contra a equipe de busca. Por isso, é importante manter a família informada das pesquisas, as dificuldades encontradas e tratar todos os envolvidos, inclusive corpos, com o maior respeito e cuidado, evitando qualquer tipo de piada, comentários depreciativos e celebrações quando se encontrar a vítima. Alguns departamentos podem contar com o apoio de psicólogos para este trabalho com a família.

Na maioria dos afogamentos em águas paradas a vítima vai estar perto do ponto de submersão. Isso foi claramente demonstrado em 1996, quando um mergulhador foi encontrado a 42 metros de profundidade no Lago Travis, Texas, aproximadamente 15 metros de onde desapareceu 17 anos antes. 
Revista Científica do Corpo de Bombeiros Militar de Pernambuco

Seção 1 - Artigos Técnico Científicos

Artigo publicado no Vol.04 №10 - Edição de JUL a DEZ 2018 - ISSN 2359-4837(online)

Versão on-line disponível em: http://www.revistaflammae.com.

Correntes em lago são raras, a exceção é em torno de barragens, vertedouros e onde os rios desembocam nestes lagos, onde a força será perto da barragem e ao redor da boca do rio. Riachos que alimentam o lago se dissipam rapidamente e sua força é quase inexistente. Ventos transferem a sua força para a superfície da água e não geram correntes e sim ondas.

Uma das reações do corpo ao afogamento é o inchaço. Quando um corpo morre, bactérias no trato digestivo irão produzir gases que resultam no inchaço. Isso pode causar uma flutuabilidade positiva ao cadáver por um período curto. Depois de ocorrer este fenômeno, o gás escapa e ele afunda novamente. Embora raro, o corpo pode boiar mais de uma vez. Durante este período de flutuação, os ventos podem mover o corpo a uma distância considerável. Existem casos em que pela profundidade, temperatura e fisiologia do corpo, este não conseguiu ficar totalmente positivo, permanecendo no fundo ou a "meia água".

A manipulação de corpos é extremamente perigosa para a saúde do MSP, devemos ter uma atenção especial com o equipamento de proteção individual e a descontaminação do mergulhador e seus equipamentos. Embora estejamos tratando de "recuperação" e não de "resgate", o MSP deve saber qual o momento de salvar vidas e qual o momento de iniciar a persecução criminal, podendo responder por omissão de socorro ou alteração de local de crime.

São sinais evidentes de morte, segundo a doutrina da maioria dos Corpos de Bombeiros do Brasil: Carbonização e calcinação do corpo; Decapitação ou seccionamento do tronco; Esmagamento completo da cabeça ou tronco; Putrefação ou decomposição e Rigidez cadavérica (IANTD, 2017).

Os dados do Brasil revelam que os afogamentos ocorrem por imprudência, má avaliação do perigo, falta de supervisão e, principalmente, por falta de educação preventiva. Temos que aprender a atuar proativamente e não há mais espaço para sermos somente reativos neste cenário. Somos um país entrando para o seleto grupo dos desenvolvidos e esta é uma necessidade 
Revista Científica do Corpo de Bombeiros Militar de Pernambuco Seção 1 - Artigos Técnico Científicos

Artigo publicado no Vol.04 №10 - Edição de JUL a DEZ 2018 - ISSN 2359-4837(online)

Versão on-line disponível em: http://www.revistaflammae.com.

atual. Programas de prevenção é a resposta que necessitamos para reduzir esta catástrofe diária - o afogamento no país. Educar a população em prevenção é fundamental e prioritário (SZPILMAN, 2011).

Gráfico 08 - Principais fatores que levaram a submersão de alvos do tipo evidências criminais materiais ou bens particulares

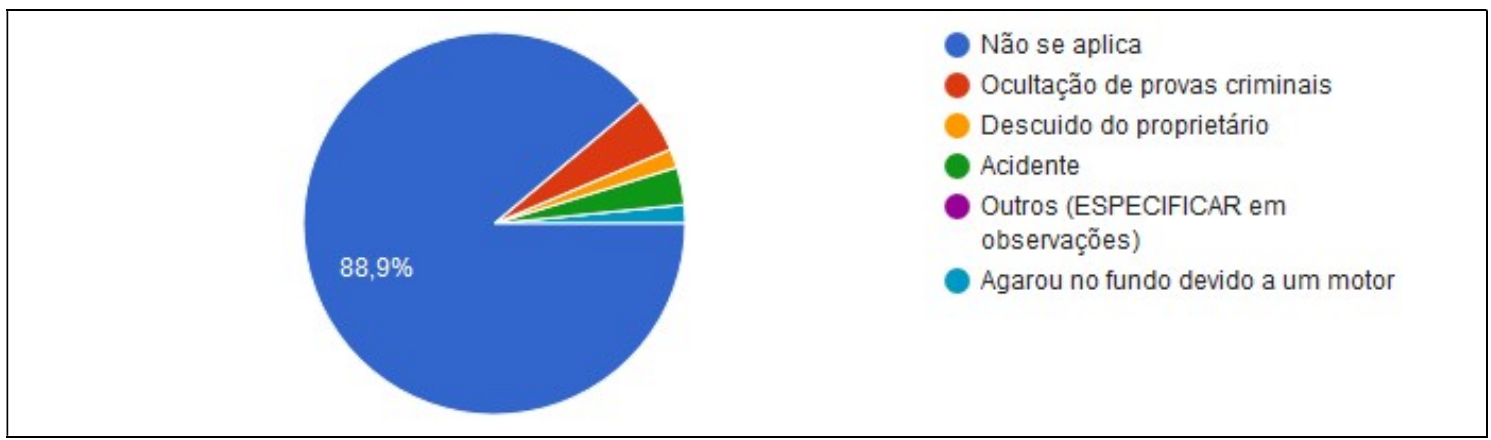

Fonte: Os autores (2017).

Os dados levantados pelas equipes de MSP do CBMES em campo durante $\mathrm{O}$ atendimento às ocorrências corroboram com as estatísticas nacionais mostrando que consumir bebidas alcoólicas e entrar em meio aquático, superestimar as habilidades de natação ou subestimar as reais habilidades na água, somadas a falta de supervisão de crianças, são as principais causas de óbitos por afogamento no estado do ES.

Verifica-se e ilustra os casos de busca e recuperação submersa de bens particulares e evidências criminais materiais, onde os principais fatores que levaram a sua submersão foram: à ocultação de provas criminais e o descuido do proprietário ou acidentes com esses bens, porém a informação de maior relevância evidenciada pela estatística é que a grande maioria dos mergulhos na área de segurança pública no CBMES $(88,9 \%)$ é com objetivo de busca e recuperação subaquática de vítimas submersas. MSP utilizam padrões de busca de forma metodológica visando a preservação de evidências e procedimentos de recuperação, usados para localizar objetos submersos 
Revista Científica do Corpo de Bombeiros Militar de Pernambuco

Seção 1 - Artigos Técnico Científicos

Artigo publicado no Vol.04 №10 - Edição de JUL a DEZ 2018 - ISSN 2359-4837(online)

Versão on-line disponível em: http://www.revistaflammae.com.

(armas de fogo, armas brancas, drogas, munições) ou outros objetos que se pensa existir em uma determinada área (carro submerso, barco, avião ou corpos). Como um Mergulhador de Segurança Pública, pode ser chamado em missões de busca, coleta de provas, reflutuação de objetos envolvidos em crimes, preservação de uma evidência criminal, automóveis ou corpos (IANTD, 2017).

Com relação aos padrões de busca e recuperação subaquática, dentre as técnicas mais utilizadas pelas equipes de serviço, observa-se a prevalência da técnica semicircular $(49,2 \%)$ e circular $(20,6 \%)$, Gráfico 9.

Gráfico 09 - Padrões de busca e recuperação subaquática adotado

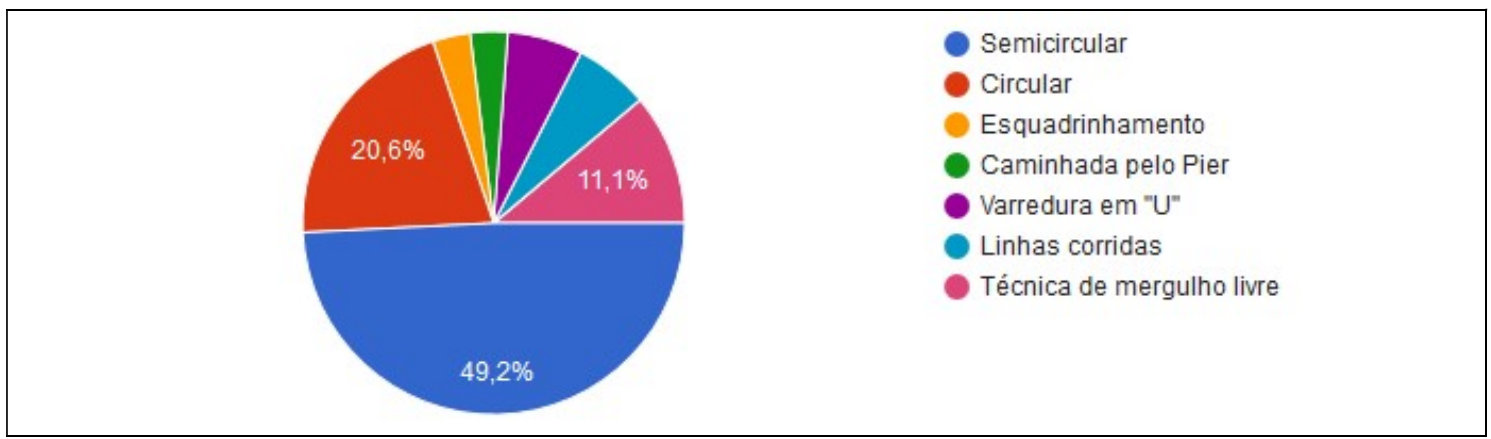

Fonte: Os autores (2017).

Tal fato deve-se muito as caraterísticas geográficas dos ambientes de atuação em que são efetuadas as imersões, uma vez que o ambiente dita o padrão de busca e não a preferência da equipe por um ou outro tipo e também pela versatilidade desses dois métodos. O padrão de busca é o "coração" da maioria das operações de resgate e de recuperação subaquática. Muitas das vezes, é impossível encontrar um objeto debaixo d'água, mesmo algo tão grande como um barco, sem estabelecer um método de busca. Existe uma variedade de padrões e métodos de busca subaquática eficazes. Dentre outros, um padrão de busca eficaz deve inicialmente, começar num ponto conhecido, cobrir uma área conhecida, e acabar num ponto também conhecido 
Revista Científica do Corpo de Bombeiros Militar de Pernambuco Seção 1 - Artigos Técnico Científicos

Artigo publicado no Vol.04 №10 - Edição de JUL a DEZ 2018 - ISSN 2359-4837(online)

Versão on-line disponível em: http://www.revistaflammae.com.

- o resultado é encontrar o objeto da busca ou confirmar que o objeto não está nessa área específica (SSI, 2016).

Todos os cenários de mergulho e de busca e recuperação subaquática são únicos. As variações no ambiente de mergulho, velocidade da corrente, métodos de entrada e saída da água podem afetar o processo de seleção para determinar o melhor método (padrão) de busca a se implantar. Apesar de existirem vários padrões de busca básicos, há também variações de cada um. Padrões de busca que foram desenvolvidos por equipes e ao longo do tempo têm evoluído em rotinas padronizadas e que são rotineiramente utilizados em todo o mundo. Estes padrões básicos provaram-se eficazes em diversas situações. No entanto, nem todo o padrão de busca irá funcionar em todos os ambientes. Em algumas situações, incluindo correntes fortes, alguns padrões de busca são extremamente perigosos de tentar. Os padrões de busca básicos incluem a busca circular, padrão de arco (Semicircular), padrão de cabo andando (Caminhada pelo píer), padrão jackstay (Esquadrinhamento), padrão tirolesa e o padrão de busca livre.

Cada padrão tem seus pontos fortes, bem como suas limitações. $O$ padrão em arco (Semicircular) é um método de busca padrão e frequentemente utilizado por agências de todo o mundo. Este padrão é fácil de usar, implantase rapidamente e é versátil em muitos ambientes diferentes (ERDI, 2016).

\section{CONSIDERAÇÕES FINAIS}

Verificou-se que o tripé composto por normatização, configuração de equipamentos e treinamento voltado para as reais necessidades do serviço é a chave para os bons resultados. Observou-se ainda que dentre os principais fatores responsáveis pelo crescente sucesso nas operações de MSP desenvolvidas na corporação estão o empenho, o comprometimento com a qualidade e a preocupação com o resultado do serviço por parte dos ME envolvidos nessa atividade. Tal dedicação é possibilitada pela exclusividade e 
Revista Científica do Corpo de Bombeiros Militar de Pernambuco Seção 1 - Artigos Técnico Científicos

Artigo publicado no Vol.04 №10 - Edição de JUL a DEZ 2018 - ISSN 2359-4837(online)

Versão on-line disponível em: http://www.revistaflammae.com.

especialização das equipes de serviço no CBMES, mesmo que as equipes de mergulho estejam inseridas em uma unidade padrão da corporação, cuja organização e gestão seguem o modelo generalista.

Enfatiza-se que possuir equipes específicas voltadas unicamente para atividades subaquáticas melhorou a qualidade e a segurança do serviço prestado. Complementa-se a este aspecto, o fato de que a DOp tem sido de fundamental importância nesse contexto, pois dentre outras funções, é responsável por estudar e emanar doutrina para as unidades operacionais da instituição nas suas diversas áreas de atuação, bem como dar suporte técnico para a especificação e compra de equipamentos, o que de certa forma compensa a não existência de uma unidade especializada.

Destaca-se ainda o respaldo e a orientação de uma normatização forte e atual (NORMERG 01) que, dentre vários pontos, prima pela segurança nas operações, padronização de equipamentos, saúde do efetivo, emprego de técnicas sistematizadas de atuação e treinamento/instrução continuada. A norma que rege a atividade de MSP do CBMES é uma iniciativa que está solidificada internamente na instituição e é alvo de pesquisa de outros vários CBM da federação que buscam no regramento estabelecido no ES fundamentação e subsídios para a melhoria da atividade de mergulho nas suas respectivas instituições.

A atividade de MSP no CBMES já vem a algum tempo sendo planejada e constantemente revisada. O Apoio do Comando Geral na aquisição de novos equipamentos, busca por capacitação e a especialização da atividade são pilares para o êxito desse trabalho prestado à sociedade.

\section{REFERÊNCIAS BIBLIOGRÁFICAS}

CBMES - Corpo de Bombeiros Militar do Espírito Santo. Coletânea de Portarias. Vitória. 2015. 
Revista Científica do Corpo de Bombeiros Militar de Pernambuco Seção 1 - Artigos Técnico Científicos

Artigo publicado no Vol.04 №10 - Edição de JUL a DEZ 2018 - ISSN 2359-4837(online)

Versão on-line disponível em: http://www.revistaflammae.com.

. Diretoria de Operações - DOp. Vitória. 2017.

. Formulário de estatística MSP. Diretoria de Operações - DOp. Vitória. 2017.

. Competências. Disponível em: <https://cb.es.gov.br/competencias> Acessado em 06 de dezembro de 2017.

Corpo de Bombeiros Militar capacita equipe de militares a realizar mergulhos técnicos de até 50 metros de profundidade com troca de gás, múltiplos patamares de descompressão e emprego de equipamentos especializados. Disponível em: <https://cb.es.gov.br/Not\%C3\%ADcia/corpode-bombeiros-militar-capacita-equipe-de-militares-a-realizar-mergulhostecnicos-de-ate-50-metros-de-profundidade-com-troca-de-gas-multiplospatamares-de-descompressao-e-emprego-de-equipamentos-especializados> Acessado em: 19 de dezembro de 2017.

Norma de mergulho - NORMERG 01. Vitória. 2017.

CLENDENEN. B. The Four R's of Managing a DCI Injury. 1996.

DIAS, D. M. Mergulho de Segurança Pública. Revista Emergência. 2016.

ERDI - Emergency Response Diving International. Emergency Response Diver I Operations Manual. 2016.

ESPÍRITO SANTO (Estado). Constituição do Estado do Espírito Santo. 1989.

FEMA - U.S. Department of Homeland Security Federal Emergency Management Agency. Public Safety Dive Team. 2007.

GAZETAONLINE. Especial Pela Vida. Índice de mortes na $3^{\text {a }}$ Ponte é o menor dentro do ES, diz psicóloga. Disponível em:

<https://www.gazetaonline.com.br/especiais/reportagens/2017/08/especial- 
Revista Científica do Corpo de Bombeiros Militar de Pernambuco

Seção 1 - Artigos Técnico Científicos

Artigo publicado no Vol.04 №10 - Edição de JUL a DEZ 2018 - ISSN 2359-4837(online)

Versão on-line disponível em: http://www.revistaflammae.com.

pela-vida 1014095823.html\#59a7df7a44efc> Acesso em: 06 de dezembro de 2017.

IANTD - International Association of Nitrox \& Technical Divers. The TAO of Public Safety Diving Manual. 2017.

MENDES, C.A. de Souza. Manual da rotina de serviço, procedimentos de atuação, segurança, comunicação e execução de padrões de busca e recuperação subaquática com utilização de cabo guia em ocorrências de mergulho de segurança pública no CBMES. Espírito Santo. 2016.

PADI - Professional Association of Diving Instructors. The Encyclopedia of Recreational Diving. 2006.

PSDiver National Standards Committee. Rev 8.0. 2014.

SESP - Secretaria de Segurança Pública. Equipe de mergulho do Corpo de Bombeiros conta com máscaras que se comunicam dentro da água. Disponível em: <https://sesp.es.gov.br/equipe-de-mergulho-do-corpo-debombeiros-cont> Acesso em: 11 de outubro de 2017.

SOBRASA - Sociedade Brasileira de Salvamento Aquático. Afogamentos. O que está acontecendo? Boletim Brasil. 2015.

SSI - Scuba Schools International. Specialty Course Instructor Dive Guide Manual. 2016. Specialty Course Search \& Recovery Manual. 2011.

SZPILMAN. D. Perfil do Afogamento. Revista Emergência. 2011.

USEPA - U.S. Environmental Protection Agency. Diving Safety Manual. 2016. 